\title{
Individual choices? Attitudes to debt and its influence on HE participation decisions
}

\author{
Wayne Bailey, University of Huddersfield
}

\section{Email: w.bailey@hud.ac.uk}

\begin{abstract}
This article explores why a group of young people living within traditionally workingclass communities choose not to participate in higher education (HE), even though they have the necessary entry qualifications, and the influence that debt has on their decisions. The research proposes that any strategies devised by the young people were about not owing money and that, at times, the amount of debt appeared to be inconsequential; being in debt was just not the accepted way of doing things. In conjunction with a general fear of debt, this paper highlights subtle and hidden disadvantages that moved beyond the question of whether the young people should participate in HE. A case study approach is adopted; with findings being drawn from a set of semi-structured interviews with 36 young people. The case study is framed by the work of Pierre Bourdieu. A particularly complex attitude to debt was highlighted; not incurring debt appeared to be a cultural rule, particularly when there was no guaranteed employment-related benefit to participation. This paper argues that similar outlooks, backgrounds, interests, lifestyles and opportunities resulted in the adoption of shared practices, common patterns of reactions and accepted ways of doing things when it came to debt.
\end{abstract}

\section{Key words}

Widening Participation, local culture debt aversion, decision making

\section{Introduction}

For many young people, making choices in relation to participation in $\mathrm{HE}$ is a complex and messy process (Reay, 2001), with non-academic factors appearing to exert the greatest influence on the most disadvantaged of qualified young people (Forsyth and Furlong, 2003). This article seeks to explore why a group of socially deprived young people, living in working-class communities in Northtown (this is a pseudonym), choose not to participate, despite having the qualifications that would give them entry to HE. Several themes emerged from the data that appeared to explain the participants' decision making. This article focuses on the influence that the fear of debt has on such decisions, and is concerned with whether there was an adjustment between the young peoples' hopes, aspirations, goals and expectations (subjective hopes) and the situation that they found themselves in as a result of their place in society (objective chances) (Bourdieu, 1990a).

\section{Debt and its influence on HE decision making}

There has been a great deal of research on debt and debt aversion and its role in individuals' choices when deciding whether to attend university. The impact 
of the cost of participation has been considered by many researchers, including Wolf (2002); Callender (2003); Dodgson (2004); Watts (2006) and Baxter, Tate and Hatt (2007), and their evidence suggests that students from workingclass backgrounds are more likely to be averse to being in debt and reluctant to accept the debt attached to being a student. In spite of the perceived value of $\mathrm{HE}$ and the positivity shown by some students towards debt as a means of enabling access to higher-level careers (Harrison, Chudry, Waller and Hatt, 2015), many young working-class people consider participation in HE in terms of risks, uncertainties, costs and benefits (Callender, 2003; Esson and Ertl, 2014). They also identify financial barriers as the most important risk (Church, Hillier, Hyde, Robinson and Watson, 2010). Moreover, Baxter et al. (2007) suggest that '.. the fear of debt could deter the very groups at whom widening participation initiatives are targeted' (p.279). Research also shows that the debt associated with HE participation is viewed as a major concern for parents, specifically in relation to their children getting into debt (Dodgson, 2004). When considering the drawbacks to university participation, Allen and Prendergas (2009) found that parents were concerned about the financing of university. The fear of their child leaving university in serious debt was a real worry, particularly if the parents were unable to support them financially. This is important because parents appear to be a strong influence on the educational decision making of their children (Daly and Thomas, 2008). Some nonparticipants have been shown to express concerns that accrued debt would pass on to family members should they be unable to repay it, and that this impacted upon their participation decisions (Jones, 2016). There is also some evidence to suggest that debt appears to be more of an issue for those who cannot draw directly on family experience of HE (Ertl, Carasso and Holmes, 2013). Parents with no direct experience of HE can be reluctant to encourage their child(ren) to consider going to university. The reasons for this have been attributed to the anticipated costs and related debt, and are partly due to fear of the unknown (Action on Access, 2009). Conner's (2001) study of non-entrants from lower social class groups emphasises a range of financial concerns. She found that there were some instances where the financial costs associated with $\mathrm{HE}$ were the main reason that her participants chose not to enter HE.

Hutchings and Archer's (2001) research found that, whilst it was generally accepted that students were 'skint' and ended up in considerable debt, there is often misinformation and vagueness about how much it costs to go and live whilst attending university. The equation, which takes account of risks, costs and benefits in relation to HE decision making, is clearly not equal for all social groups, as the balance between benefits weighed against risks and costs is structured differently across social classes (Archer, 2003). For example, Melcalf (1993) discusses how those from less affluent backgrounds may regard $\mathrm{HE}$ as irrelevant to their future, as opposed to those from more affluent backgrounds who view it as being important for securing better job prospects. As Voigt (2007, p.105) explains '...higher education is riskier, more costly and less beneficial, and hence a worse 'investment' for non-traditional students than it is for their middle-class peers'.

The financial costs of participation are clearly an issue, with better-paid jobs as a result of participation in HE being far from certain. It can be unclear how young people from lower socio-economic groups benefit from HE participation (Watts and Bridges, 2006). It seems that the decision to go to university 
involves more risk for those from working-class backgrounds than for their middle-class counterparts (Baxter et al, 2007), and that the financial costs of $\mathrm{HE}$ can outweigh any future financial returns (Watts, 2006). Some nonparticipants have struggled to map the transition from HE participation to well paid, high quality employment. Citing examples of unemployed or low earning graduates, some non-participants have suggested that low paid jobs could be gained without participating in HE. Some young people have been shown to view participation as poor value, as there is no guaranteed return on investment (Jones, 2016).

\section{The research study and methodology}

\section{Context}

In order to offer some context, and to better understand the influence that debt has on HE participation decisions, the HE context in the United Kingdom (UK), along with some of the negative social indicators that contribute to Northtown's social profile, should be considered. The last ten years has seen significant changes in the size and shape of the UK higher education sector. Full-time student numbers have increased and now make up nearly threequarters of the student body, with $55.1 \%$ of undergraduates being female. Parttime numbers have declined, and employment figures show that graduates' unemployment rates are consistently lower compared to non-graduates. Over the last 10 years, the background of students has become more diverse, whilst the proportion of 18-year-old entrants remains high; the entrant rates vary by student background with gaps of up to $32 \%$. The Higher Education Funding Council for England's (HEFCE) 1 POLAR 2 classification shows how the chances of young people entering HE varies by where they live. HEFCE's classification comprises five quintile groups of areas ordered from ' 1 ' (those wards with the lowest participation) to ' 5 ' (those wards with the highest participation), each representing $20 \%$ of the UK young cohort. They highlight that those 18 year-olds in quintile 5 were 2.7 times more likely to participate in HE than those in quintile 1(HEFCE, 2013; Universities United Kingdom (UUK), 2015).

Northtown is ranked the 39th most deprived areas in the country (English Indices of Deprivation, 2015), and key influences on Northtown's high level of deprivation are the number of people with low-level or no qualifications, with only $13 \%$ of young people staying in education post 16 (One Barnsley, 2008; Barnsley Metropolitan Borough Council, 2015). Personal debt is a particular problem in Northtown; during 2014/15 Citizens Advice helped people manage $£ 14,753,578$ of problem debt (Citizens Advice, 2015).

Northtown underperforms on many social and educational indicators; consequently, it appears to suffer from high levels of social deprivation (Townsend, 1993) and this indicates that the young people involved in this study lack certain freedoms and experience barriers to full participation in community life (Bassuk and Donelan, 2003). Being socially deprived, it is

\footnotetext{
${ }^{1}$ HEFCE funds and regulates universities and colleges in England. They invest on behalf of students and the public to promote excellence and innovation in research, teaching and knowledge exchange (HEFCE, 2016).
} 
possible that the participants are denied rights to an equal share in the benefits of social progress, including the right to HE participation (Townsend, 1993). All participants lived in quintile 1, low-income neighbourhoods that were in the top $10 \%$ of the Index of Multiple Deprivation ${ }^{2}$. They were viewed as being from traditional working class backgrounds (Beider, 2011; Garner; 2011). Being from traditional working class backgrounds, the participants appeared to have limited cultural and economic capital and a restricted range of social contacts (Savage, 2013). The participants lived in neighbourhoods where participation rates in HE ranged from 15.8 to 20.6\% (HEFCE, 2013).

\section{Theoretical framework}

This article follows a case study approach in order to examine particular subjects and themes linked to debt aversion. In particular, it focuses on how debt influences HE participation decisions (Gray, 2014). The case study draws on the work of Pierre Bourdieu to help explore assertions about working class culture and attitudes. Bourdieu suggests that the two orders, objectivity and subjectivity, are connected through actual social practices, with objective social relations being produced and reproduced within specific situations (Bourdieu, 1977). Consequently, whilst this article considers the subjective points of view of the young people with respect to the influence of debt on their nonparticipation, it also pays attention to factors which appeared to have shaped and moulded their decisions. This article utilises some of Bourdieu's relational thinking tools to interrogate the decision making of the participants. Particular attention was paid to practice, habitus and symbolic violence, '...to effect the synthesis of objectivism and subjectivism...' (Wacquant, 2008, p. 267).

\section{Sample}

Three institutions: Town Sixth Form, Village Sixth Form and West Sixth Form (pseudonyms) offer sixth form education ${ }^{3}$ in Northtown. Two institutions were selected for this study. They were selected because they had students who had chosen not to participate and who resided in low-income, quintile 1 neighbourhoods that were in the top $10 \%$ of the IMD. West Sixth Form was not chosen as it did not fit these parameters. Town Sixth Form is part of a large tertiary college serving Northtown and surrounding areas. $80 \%$ of school leavers in the town attend the college, which is the main provider of post-16 education. Northtown College is seen as being highly effective by Ofsted (Office for Standards in Education, Children's Services and Skills), particularly with regard to raising learners' aspirations and supporting them to succeed, with learners of all ages achieving well at the majority of levels. The college has been recognised as one of the best colleges in the UK by Ofsted (Ofsted, 2010).

\footnotetext{
${ }^{2}$ The Index of Multiple Deprivation is the official measure of relative deprivation for small areas (or neighbourhoods) in England. The Index of Multiple Deprivation ranks every small area in England from 1 (most deprived area) to 32,844 (least deprived area) (Department for Community and Local Government, 2015).

${ }^{3}$ Sixth forms provide academic education to 16 to 18 -year-olds enabling them to progress to university or higher level vocational education (Association of Colleges, 2017).

${ }^{4}$ OFSTED inspects and regulate services providing education and skills to learners of all ages (OFSTED, 2016).
} 
The other site is Village Sixth Form, a relatively newly established provider of post-16 education that opened in 2006. The overall effectiveness of the Sixth Form was satisfactory in 2009; however, in February 2014, it was viewed as being inadequate (Ofsted, 2014). Village Academy is smaller than most secondary schools.

Thirty-six participants were interviewed from the sixth forms of these two institutions. Five participants were 17 years old and thirty-one were 18 years old. At the Village Sixth Form, I interviewed all those students that could attend university, but had chosen not to (22), and at Town Sixth Form, I interviewed students who had chosen not to participate in HE who were prepared to be interviewed (14). All participants were white British. The table below summarises participant information:

Table 1

\begin{tabular}{|l|l|l|l|}
\hline Institution & $\begin{array}{l}\text { Nos of } \\
\text { participants }\end{array}$ & Age & Gender \\
\hline $\begin{array}{l}\text { Village Sixth } \\
\text { Form }\end{array}$ & 22 & $\begin{array}{l}18(17 \text { participants }) \\
17 \text { participants })\end{array}$ & Male 9 participants \\
Female 13 participants \\
\hline Town Sixth Form & 14 & $18(14$ participants $)$ & $\begin{array}{l}\text { Male 7 participants } \\
\text { Female 7 participants }\end{array}$ \\
\hline
\end{tabular}

\section{Methods, data collection and analysis}

The purpose of the data collection was to gather information about the participants' practices, attitudes and other key characteristics and influences. Using semi-structured interviews allowed rich information that was personal and unique to the participants to be collected (Arksey and Knight, 1999). However, in carrying out semi-structured interviews, this study takes account of the criticisms that have been levelled at them such as bias, inaccuracies due to the poor recall of participants or the fact that they may have given the answer that they deemed to be appropriate (Gray, 2014).

The interviews were designed in such a way as to draw on the findings from the literature discussed above, whilst taking into account the subject matter being researched and the age and education level of the participants. Participants were asked to consider what they intended to do when they left college/school, emphasis was placed on both their immediate and future aspirations/ambitions and the reasons they gave for their decision making. Of particular interest was whether the participants had considered participating in $\mathrm{HE}$, and if not, whether there was anything that could have been put in place that might have led to them to participate. They were also asked to consider what they thought university life might involve. An interesting aspect of this research is that it spanned two British governments, with some interviews taking place prior to 2010 when fees were 3000 GBP and a number being carried out after the subsequent hike in fees to 9000 GBP. Significantly, this research found no real change in the participants' relationships to debt, whether interviewed before or after 2010. Whilst the post-2010 participants continued to be debt-averse, the amount of debt seemed to be of limited significance. 
A general thematic approach was utilised to analyse these data (Braun and Clarke, 2006). This approach was followed because it is compatible with a case study approach and Bourdieuian framework in that it allowed the examination of the ways in which events, realities, meanings and experiences impact upon the participants' decision making. As Braun and Clarke suggest, (2006, p.85): '...thematic analysis...seeks to theorise the socio-cultural contexts and social conditions that enable the individual accounts that are provided'.

The analysis undertaken was not viewed as a process that was linear in nature; it was more of what Braun and Clarke call a '...recursive process, where movement is back and forth as needed, throughout the phases' (p.86). Whilst I was not looking for a predetermined list of specific themes, I did take account of key Bourdieuian concepts that might help to explain the non-participation of the participants. For example, when reading the transcripts, I looked for themes that might help to explain the participants' practices and how the participants' habitus influenced their decision making pertaining to debt. For Bourdieu, practice is the carrying out of an activity that is formally named. Practices have structures, limits, points of harmony and meaning. I was looking for examples of common patterns of reaction that the participants shared, what they viewed as being acceptable ways of doing things when it came to debt (Bourdieu, 1977, 1984 and 1990a). By considering the participants' habitus, I was able to begin to understand their inclination towards certain dispositions to actions and values (Bourdieu, 1977, 1993).

Consideration was also given to symbolic violence. When Bourdieu discusses symbolic violence, he alludes to the imposition of culture on groups or classes in a manner that makes them experience it as being legitimate. It is the education system that fulfils the function of legitimisation through the pedagogic process. Therefore, I was interested in the pedagogic actions that were carried out within the participants' family structure and within their sixth forms, and the impact this had on their decision not to participate (Bourdieu, $1973 ; 1990 b)$

\section{Ethical issues}

Ethical considerations were also taken account of in this study, based on the British Education Research Association (BERA) guidelines. Participants were treated fairly, sensitively, with dignity and within an ethic of respect and freedom from prejudice. The right of any participant to withdraw from the research for any or no reason and at any time was recognised, and they were informed of this right prior to the interview taking place. Confidentiality and anonymity were assured, as was the participants' entitlement to privacy (BERA, 2011). The specifics of individuals were not discussed with anyone and each participant was allocated a number that has been used when reporting their opinions and viewpoints.

\section{Findings}

The quotes that are referred to within this article were chosen because they best represented the themes and the participants' points of view. The interviews uncovered a wide selection of information relating to different areas and aspects of debt, and the themes that emerged from the data were: indebtedness; 
influences on action; cost versus benefits and the importance of family; these are used to structure these findings. Each theme has been analysed and the 'story' that emerged from it told.

\section{Indebtedness}

The majority of participants (25/36 participants) showed complex attitudes towards debt. The idea of being in debt was viewed as a major risk that they appeared to be reluctant to expose themselves to:

'...it's hard, isn't it, for students and stuff and you've got all this debt hanging over you when you've done and I just don't want that. I don't know, I just don't like thought of having it, having debt. It fills me with dread.' (Participant 16)

They considered participation in HE in terms of risks, costs and benefits. This resonates with the work of Baxter et al., (2007) who discuss the additional risk attached to HE participation for people from working-class backgrounds than for their middle-class counterparts. In Distinction (1984), Bourdieu refers to the lifestyles of the working class and the choices that they have to make because of their background, and that this emanates from a deprivation of necessary goods that is inescapable. Consequently, there is an inevitable resignation to the limits that are placed on their lives, and thus a forced contentment that is produced due to working-class life. The working-class backgrounds of the participants appear to have exposed them to specific dispositions and different material conditions that have instilled preferences that may be unconscious (Bourdieu, 1984). Participant 9 gets to the nub of this issue:

'...but I think for everybody especially coming from here, and I'm not saying Northtown is as deprived as what everybody makes it out, it isn't as bad as what everybody says but I think coming from an area like this where traditionally people haven't got that much money, it is a problem...I think that's the same for everyone to be honest....'

The participants did not want to be what a significant number (13/24 participants) of them termed as 'lumbered' or 'saddled' with a debt that they would not be able to pay off. It appears that the majority of the participants associated HE participation with having a '...massive bill that goes on forever' (Participant 16).

\section{Influences on action}

There were clear commonalities that related to values, as well as their knowledge of, and experience of, debt in one way or another. Many of the participants had stories that related to debt; it was viewed as being 'corrosive' (Participant 6). They appeared to have a particular set of beliefs and values with regard to debt. Implicit within the majority of the interviews was the fact that people did not have much money, and if they could not afford it, then they should not spend it. Their habitus seemed to reflect the ideals of their family and local community more broadly; not being in debt was an accepted way of doing things. Common meanings seemed to have accumulated over time that had been influenced by their local culture. Their local culture seemed to provide them with a sense of identity that facilitated common understandings, 
traditions that helped to build a sense of local identity and solidity between them, their family and a wider network (Brennan, 2005).

The thoughts of participant 24 best illustrate this:

'No-one wants to be in debt really, do they? Yeah, that's another thing that I didn't want, to be leaving owing money so really .... I don't know how to explain it. Just knowing you're in debt and knowing that you owe out money really, and it takes ages to pay back. That's it...that's not how we do it, we don't do debt.'

The idea of having to spend years paying back a debt accrued as a result of HE participation appeared to be just unacceptable. The idea that debt is '...always there' and 'at the back of your mind' was discussed and the thought of this was disconcerting. Any strategies devised by the participants were about making money; the preference was always earning money not '...owing it out' (Participant 18).

University debt was seen as a debt for life, and participants seemed uncomfortable with being in such debt without being able to gain employment and pay it off. As participant 21 suggests:

'...all cost issues and having to borrow off student loans and when you have to work, you have to give it back and things. It's a lot of money. It's getting in debt before I can even get a job. It makes me feel like I wanna run away and not go to university.'

The data suggested that the majority of participants had a particular value system that impacted on their practice and orientated them towards actions that ensured that they were not in debt. They had common patterns of reaction that they shared and an acceptable way of doing things that appeared to have become standardised (Bourdieu, 1977, 1984 and 1990a). The participants' 'way of life' seemed to be broadly represented by rules and expected behaviours, and these commonalities related to the values, knowledge and experience that they held. The quotes below further illustrate what the participants hold dear, where they think they belong, and how this influences the choices that they make (Brennan, 2005).

'They don't want me to go 'cause I've never been away for that long, and they don't like thought of me going away like that. My mam wants me to stay with them. Family is...really important to me; I trust them. I know if I have any problems about owt that they will sort it out for me. Me and my mam are exactly the same. I don't know what I'd do if I didn't see her every day to have a natter about, well nothing really, just a natter.' (Participant 16)

'Everyone I know lives in Northtown...why would I want to leave, when I've lived here all of my life... I belong here.' (Participant 20)

'...what's point of going...even if I did, I won't leave Northtown. We've always lived in the same place; it's where I belong, in Northtown. Anyway, I couldn't afford to leave even if I wanted to. My mam hasn't got any money. Like my granddad says...born in Northtown, die in Northtown...that suits me fine.' (Participant 27)

'I just couldn't leave my home and live on my own. I'd miss everybody...I feel safe with my mam and dad...we think the same. I've lived with them all of my life...we do just about everything together. No, I just couldn't leave them.' (Participant 31)

\section{Cost versus benefit}


For the majority of the participants, there appeared to be more subtle and hidden disadvantages of debt that moved beyond the question of whether they should participate in HE. It seemed clear that debt alone was not their main consideration; HE was a guaranteed cost, without a guaranteed benefit. Unless there was a guaranteed extrinsic reward, specifically employment-related, then the participants gave the impression that they had no motivation to participate in HE. The attitudes of participants 14 and 16 are typical of the viewpoints held by the majority of the participants:

'Employers are looking for people with experience and if you spend three years at university, it's not real life experience.'

'I've got work at Tesco...I'm gonna train up. I just hope I do well in the future and I hope I do well without going to university 'cause I really don't think I need to go to be honest, and that's my opinion...I'm gonna work my way up.'

The participants seemed to be carrying out something that can only be described as a cost-benefit analysis. They were worried about incurring debt and then being unable to secure what they saw as an appropriate job to allow them to pay off the debt. There was an emphasis on value for money. This resonates with Bradley and Miller (2010), who explored the subjective beliefs and values of young people from similar backgrounds. Much like them, the participants appeared to show a definite ambivalence about the career benefits of a degree, and there was a strong belief from many of the participants that they were just as likely to get a job without a degree. The participants seemed aware that the decision to go to university involves a certain amount of risk (Baxter et al., 2007; Voigt, 2007), and they appeared worried that the financial costs of HE were likely to outweigh any possible future financial returns (Watts, 2006). The majority made reference to graduates who, having left university, were unable to secure employment that related to their studies. Many of the participants had a particular story to share that alluded to graduates not being able to find 'the right' job. Participant 6 referred to a cousin who had participated in HE and studied for a sports science degree. He referred to his cousin as being '...lumbered with debt because sports science never caught on'. Employers were '...looking for people with experience and if you spend three years at university, it's not real life experience' (Participant 9). They proposed that the three years would have been better-spent gaining experience and '...moving up the ladder' (Participant 12). Participant 14's attitude to this issue reflects the viewpoint held by the majority of the participants:

'....and even with a degree with climate the way it is now, there's no guarantee I'll get a job...so I can't pay my debt off so I'm looking at paying debts 'til I'm near retirement. I may as well just get a job...'

There seemed to be evidence of cultural reproduction in the participants' attitudes, beliefs and common understanding of debt, costs and benefit. For the participants, the situation that they found themselves in, coming from workingclass backgrounds and living in socially deprived areas of Northtown, seemed to have influenced their HE aspirations as well as their hopes and goals more broadly, and this resulted in them being steered towards the world of work in one way or the other. Much like Bourdieu and Passeron (1977) suggest, the participants seem to have internalized the objective chances which they face 
and, as a result, considered futures that they believed to be realistic. As Bourdieu points out:

Outlooks on the future depend closely on the objective potentialities which are aspects defined for each individual by his or her social status and material conditions of existence.

(1977, p.53)

For the majority of the participants, their 'subjective hopes' regarding participation in HE seem to have adjusted to the 'objective probability' of participation. The participants presented realism about their future and the majority only seemed prepared to attempt what they viewed as being possible without accruing debt. The participants' beliefs, outlooks and practices seem to have been influenced by an array of stimuli, which impacted upon their educational choices.

\section{The influence of social networks}

Both sixth forms, it would seem, tried to inform the participants about, and shape their perception of, what participation in HE involved. There was evidence of them trying to prepare participants by providing relevant experiences and insight into university life. As participant 23 discusses:

'...they're always on about it...they are trying to brainwash us...'

The majority of participants had attended university talks and some had attended open days at a variety of local HE providers. However, whilst HE participation appeared to be engendered as an entitlement by their place of study, it seems that the participants' thoughts were never far away from costs and debt. As participant 14 points out:

'If I do go to university, it'll cost me a lot of money so I'll be in a lot of debt...that is not what I want...'

All participants cited discussing the financial implications of debt with their friends and wider family members, but particularly parent(s). There were several examples of '...horror stories...' (Participant 6) when it came to debt, which had been articulated to them by members of their close family. It appeared that the motivations behind non-participation were based on the expectation that their family would suffer financially, should they participate. Key issues often seemed to be discussed in terms of the collective and not the individual. It seemed that a sense of family solidarity had been inculcated within the majority of the participants, and this appeared to be an influencing factor when it came to HE participation. An apparent personal decision not to participate in HE was influenced by both cultural and social factors, and was, in fact, a collective endeavour. The thoughts of participants 16 and 26 best illustrate this:

'I asked my dad if he would really be happy if I went to university and he said so, but he said that he was right worried about the cost of uni and had I thought about getting a job, or even staying at college. My mam really doesn't want me to go 'cause she says she will miss me too much. She says I can go if I want though and not to worry about the cost cos we're all in it together.'

'I couldn't go...even if I wanted to. Both my mum and dad would look after me, but I haven't got a clue how they would pay. It makes much more sense not going. If I get a job, I could give them money and not take it off them.' 
The participants' family upbringing seems to have shaped their habitus in terms of their attitude to, and how they feel about, being in debt. This is well illustrated by participant 4 :

'My mam says debt's right bad; she won't even have a credit card. She says she got caught out in the past.'

The social structure of the participants' local community, such as their wider network of social relationships (family/friends), seemed to have, in part, shaped their attitude to the financial implications of $\mathrm{HE}$ participation. Participant 29 gets to the nub of this issue:

'...most people are just interested in getting by, we haven't got the money for uni none of us...obviously this is a massive issue for us all. I've talked to my mam and dad and family and they all seem to be saying that getting a job is best way ...I'll be making money then and won't owe folk.'

As touched upon, symbolic violence's central proposition involves pedagogic actions which are carried out within the framework of social structures by peers, families and schools who inculcate meaning. It involves both the exclusion and inclusion of specific ideas (Bourdieu, 1973). The pedagogic actions that have been carried out within the participants' family structure with regard to debt seem to have reproduced the same attitudes to it. The participants have produced dispositions that ensured what were seen to be appropriate responses to the stimuli presented, with the rules, values, behaviours and attitude to debt appearing to be shaped by their family (Bourdieu and Passeron, 1977). The idea of having to spend years paying back a debt accrued as a result of HE participation appeared to be just unacceptable. The preference was always earning money, not owing it. The strategies they devised appeared to have been discussed with, and shaped by, various sections of the participants' social network, but particularly with their family. Participants 18 and 35 illustrate this well:

'...my dad's advised me that I don't really need to go and I could get into jobs quite easily and stay at home with him and my mam.'

'Whilst I do believe them, when they tell me to go, I'm not sure that I really believe them. My mam is always on about Tesco's and how I could get a good job there and work myself up.'

\section{Discussion: Complex attitudes to debt}

All participants voiced major concerns about the financial risks and implications of attending university and the prospect of debt. The cost of participation and financial concerns have been considered by many researchers within the last 10 or more years, yet little seems to have changed to alleviate widespread apprehension about the prospect of debt. Participants in this study seemed to treat HE participation as they would buying any other consumer item. If they bought an HE experience, then they expected a job - a good job at the end of it. There had to be a guaranteed benefit to participation; specifically, a career benefit. The participants' main motivations seemed to be to make money, not to be in debt, as that was just not the right way to do things; debt equalled risk and uncertainty. It almost felt that for the participants and their families, that not incurring debt was expected - a cultural rule. University debt was seen as a debt for life, and there were no guarantees that 
appropriate employment would be secured locally that would enable them to pay back an incurred debt. The expectation of such a debt seemed to have been one of the main motivations behind the participants opting to look for a job and not to participate in HE. It was an authorised strategy of action (Swidler, 1986). There is evidence to suggest that such dispositions and behaviour could, as a result of working-class locality and identity, be restricted in a manner that could be socially limiting (Ingram, 2009). This could also impact on the participants' educational aspirations due to the world-view being represented by their locality (Connolly and Healy, 2004).

Perhaps by virtue of being from working-class, socially deprived backgrounds, the majority of the participants appeared to have had similar experiences. Such similarities seemed to be the result of the opportunities they had been afforded, because of the social relationships they had fostered and the structures they had encountered and this impacted on their decision-making. Enculturation or social learning appeared to have taken place both within, but particularly between, generations with vertical transmissions between parent(s) and some horizontal transmissions between peers (Patterson, 2010). They favoured no debt over debt, irrespective of the amount or the reason for the debt. This reinforces the work of Callender and Jackson (2008), who pointed out that choice can be constrained by costs, with students from lower income families fearing debt, and that this played a pivotal role in their decisions.

Developing strategies that helped to prevent debt seemed to have been conditioned by the participants' habitus (Bourdieu, 2000). The participants' habitus was a kind of transforming machine that seemed to lead them to 'reproduce' their social conditions (Bourdieu, 1993). Their habitus predisposed them to behave in a particular manner when it came to debt; again, there were cultural rules. Employment was much more likely to bestow economic, social and cultural capital (Bourdieu, 1986). This was a source of anxiety for the participants; they seemed to want guarantees that the substantial outlay that was attached to participation would lead to a guaranteed job. As there was no guaranteed return on their investment in terms of a well-paid job (Jones, 2016), the majority of participants struggled to justify the potential debt attached to participation. They voiced a particular set of beliefs and values pertaining to debt, a simple mantra: if you cannot pay, then do not buy. The informal learning that appeared to have taken place within the family, particularly between the participants and their parent(s), is important. The key element of informal learning. according to Cullen, Batterbury, Foresti, Lyons and Stern (2000), is social; it is not something that is wholly individual in nature (Eraut, 2000). The apparent socially embedded nature of the participants' learning (Field and Spence, 2000) gave the impression that it had taken place within everyday life, and within particular family situations (Mills and Kraftl, 2014). Informal learning between participants and parent(s) pertaining to debt and the financing of university appeared to be far more persuasive than anything that they had been told by their respective sixth forms about the value of $\mathrm{HE}$. Parent(s) who were unable to draw directly on an HE experience (Ertl et al., 2013) seem to have been a particularly strong influence on the participants' decision making process (Daly and Thomas, 2008). They appeared to be worried about any accrued debt, as they were not in a position to support their child(ren) financially (Allen and Prendergas, 2009). Despite attending talks at their respective sixth forms and university open days, the majority of 
participants tended only to concentrate on what might be viewed as being the negatives attached to participation. For example, they were quick to discuss their parent(s)' predisposition to employment over HE participation.

The informal learning that took place within the participants' family seemed to be particularly powerful and complex, and to influence patterns of behaviour, thought and feelings about the risks of debt (Haggart, 2000). The participants seem to have learnt about roles, relationships, responsibilities and decision making from their parent(s). Their opinions had weight; a particular gravitas that seemed to ensure that the participants wanted to do the best by their family. In this particular instance, the best for their family was not being in debt. Debt was not viewed as an individual issue; any debt accrued through HE participation was seen as a collective family debt.

As a result of the dispositions and values that the participants possess, they appeared to respond to cultural rules and contexts in similar ways. For the majority of the participants, an obvious action in terms of accruing debt was not to accrue debt: this was the 'natural way' (Bourdieu, 2000). The participants' values were important and significant pieces of cultural equipment; they organised and anchored patterns of action and fine-tuned the regulation of action within their established way of life (Swidler, 1986).

As touched upon, participants continued to be debt-averse whether they were interviewed either pre or post the hike in fees in 2010. The amount of debt seemed to be of limited significance; the outcome was the same - debt. This is interesting, as once more their habitus may have predisposed them to behave in a particular manner in relation to debt. Their learning, in relation to debt and its implications, seemed to have been situated within their own particular context and whilst there was no evidence of intentional teaching about debt and its implications, as a result of their 'lived experience' they appeared to have a tacit, taken-for-granted understanding of debt and its implications, and this seemed to influence their decision making and actions (Eraut, 2000).

\section{Conclusion}

This article has discussed how a general fear of debt, in conjunction with an expectation that the costs associated with HE participation should lead to a guaranteed job, influences decision making. It has indicated complex attitudes towards debt and a particular set of beliefs and values that relate to the financing of $\mathrm{HE}$. This research indicates that debt alone was not the main consideration; HE was a guaranteed cost, without a guaranteed benefit. Unless there was a guaranteed extrinsic reward, specifically employment related, there was no motivation to participate in HE.

This article has proposed that any strategies devised by the young people were about making money and not owing money and that, at times, the amount of debt appeared to be inconsequential; being in debt was just not the accepted way of doing things. Significantly, evidence suggests that students from working-class backgrounds are more likely to be averse to being in debt and reluctant to accept the debt attached to being a student. Moreover, indebtedness is viewed as a major risk by many working-class young people and their families. In spite of the perceived value of HE alluded to by the participants' 
respective sixth forms, the young working-class adults who participated in this study still seem to consider participation in $\mathrm{HE}$ in terms of risks, costs and benefits (Callender, 2003), and their decision making seems to be heavily influenced by their family.

There was no suggestion of the participants gambling by participating in order to gain additional capital in the long run. The situation that they found themselves in, coming from working-class backgrounds and living in socially deprived areas of Northtown, seemed to have influenced their HE aspirations as well as their hopes and goals more broadly, and this resulted in them being steered towards the world of work in one way or the other. Much like Bourdieu and Passeron (1977) suggest, the participants seem to have internalized the objective chances which they face and, as a result, considered futures that they believed to be realistic. For them, it was a necessity that any future possibilities did not lead to debt, something they associated with HE participation.

Ultimately, this article has argued that, in spite of the conditions in, and characteristics of, their local community, the majority of participants appeared to value education broadly. Their expectation, however, was that any education that was undertaken had to lead to something, and could not be education for education's sake. Extrinsic rewards, particularly employment-related rewards, were of key importance. None of the participants talked about loving a particular subject or the potential for personal growth, should they participate. Their construction of HE was that it was high cost, both financially and socially, and that these costs may outweigh future benefits (Hutchings and Archer, 2001; Watts and Bridge, 2006). Much like their family and friends, the participants seemed to have similar outlooks, backgrounds, interests, lifestyles and opportunities, which resulted in the adoption of shared practices, common patterns of reactions and accepted ways of doing things when it came to debt.

This research, in concentrating on the participation decisions of suitably qualified young people who live in working-class, socially deprived communities, has helped to highlight an important aspect of widening participation that has not been extensively researched. A limitation, however, is that there is no data on how the prospect of debt influenced similar students that did participate in HE. There is clearly a need for future research in this area that will further illuminate the issue. 


\section{References}

Action on Access (2006) Making a difference: the impact of Aimhigher,

Engagement of parents and carers [Online]. Available at:

http://actiononaccess.org/wp-content/files_mf/engagement.pdf (accessed:

12 October 2016).

Allen, M. and Prendergas, Y. (2009) Research into the Engagement of Parents and Carers of Aimhigher Children Supporting decision making in the transition to higher education [Online]. Available at:

http://www.heacademy.ac.uk/resources/detail/aim_higher/AHGMEngage Parents_and_Carers_of_AH_Children (accessed: 12 October 2016).

Archer, L. (2003) 'Social class and higher education' in Archer, L., Hutchings, M., and Ross, A. (eds) Higher education and social class: issues of exclusion and inclusion, London: RoutledgeFalmer.

Arksey, H. and Knight, P. (1999) Interviewing for Social Scientists, London: Sage.

Association of Colleges (2017) Sixth Forms [Online]. Available at: https://www.aoc.co.uk/sixth-form-colleges (accessed: 14 December 2017).

Barnsley Metropolitan Borough Council (2015) Indices of Multiple Deprivation (IMD) 2015 Education, Skills \& Training Domain Briefing [Online]. Available at: https://www.barnsley.gov.uk/media/3418/imdbriefing-on-education-2015.pdf (accessed: 20 November 2017)

Bassuk, E. and Donelan, B. (2003) 'Social Deprivation' in Green, B., Friedman, M., de Jong, J., Soloman, S., Keane, T., Fairbank, J., Donelan, B., and Frey-Wouters, E. (eds) Trauma Interventions in War and Peace: Prevention, Practice and Policy, New York: Kluwer Academic/Plenum Publishers.

Baxter, A., Tate, J. and Hatt S. (2007) 'From policy to practice: pupils' responses to widening participation initiatives', Higher Education Quarterly, 61, 3: 266-283.

Beider, H. (2011) White working-class views of neighbourhood, cohesion and change [Online]. Available at: http://www.jrf.org.uk/publications/workingclass-views-neighbourhood (accessed: 14 May 2014). 
Bourdieu, P. (1973) 'Cultural Reproduction and Social Reproduction in Knowledge Education and Cultural Change' in Brown, R. (ed.) Knowledge, Education, and Cultural Change, London: Tavistock.

Bourdieu, P. (1977) Outline of a Theory of Practice, Cambridge: Cambridge University Press.

Bourdieu, P. (1984) Distinction, Cambridge: Harvard University Press.

Bourdieu, P. (1986) 'The forms of capital'. in Richardson, J. (ed.) The handbook of theory: Research for the sociology of education, New York: Greenwood Press.

Bourdieu, P. (1990a) The Logic of Practice, Cambridge: Polity.

Bourdieu, P. (1990b) In Other Words: Essays Towards a Reflexive Sociology, Stanford: Stanford University Press.

Bourdieu, P. (1993) Sociology in Question, London: Sage.

Bourdieu, P. (2000) Pascalian Meditations, Cambridge: Polity.

Bourdieu, P. and Passeron, J-C. (1977) Reproduction in Education, Society and

Culture, London: Sage.

Bradley, J. and Miller, A. (2010) 'Widening Participation in higher education: constructions of going to university', Educational Psychology in Practices, 26, 4: 401-413.

Braun, V. and Clarke, V. (2006) 'Using thematic analysis in psychology', Qualitative Research in Psychology, 3, 2: 77-101.

Brennan, M. (2005) The Importance of Incorporating Local Culture into Community Development EDIS, Gainesville: University of Florida.

British Educational Research Association (2011) Ethical Guidelines for Educational Research [Online]. Available at: http://content.yudu.com/Library/A2xnp5/Bera/resources/index.htm?referre rUrl=http://free.yudu.com/item/details/2023387/Bera (accessed: 1

September 2016).

Callender, C. (2003) 'The Contradictions of Higher Education Policy', ESRC Research Special, The Edge, 14:10-12.

Callender, C. and Jackson, J. (2008) 'Does the fear of debt constrain choices of university and subject of study?', Studies in Higher Education, 33, 4: 40529.

Church, A., Hillier, Y., Hyde, S., Robinson, C. and Watson, J. (2010) Communities and Widening Participation Research: Report to HEFCE, Brighton: University of Brighton.

Citizens Advice (2015) Advice changes lives: Making a difference in Barnsley [Online]. Available at: https://barnsleycab.org.uk/wpcontent/uploads/2015/10/CAB-Annual-Report-14-15.pdf (accessed: 10 November 2017).

Connolly, P. and Healy, J. (2004) 'Symbolic violence, locality and social class: The educational and career aspirations of 10-11-year-old boys in Belfast', Pedagogy, Culture and Society. 12, 1: 140-52. 
Cullen, J., Batterbury, S., Foresti, M., Lyons, C. and Stern E. (2000) Informal Learning and Widening Participation: Report to the Tavistock Institute, (Report No. 191). London: The Stationary Office.

Daly, A. and Thomas, L. (2008) What influences vocational choices?, Report to Aimhigher, Greater Merseyside Widening Participation Research Centre. Liverpool: Edge Hill University.

Department for Community and Local Government (2015) The English Index of Multiple Deprivation (IMD) 2015 [Online]. Available at: https://www.gov.uk/government/uploads/system/uploads/attachment_data/ file/465791/English_Indices_of_Deprivation_2015 _Statistical_Release.pdf (accessed: 20 October 2017).

Dodgson, R. (2004) 'Parents and Higher Education in the North East of England: Attitudes, Concerns, Influence and Engagement', Journal of Access Policy and Practice, 2, 1: 5-23.

Ertl, H., Carasso, H and Holmes, C. (2013) Are Degrees Worth Higher Fees? Perceptions of the Financial Benefits of Entering Higher Education: Report to SKOPE, (Report No 117). Oxford: University of Oxford.

Esson, J. and Ertl, H. (2014). 'No point worrying? Potential undergraduates, study related debt and the financial allure of Higher Education'. Studies in Higher Education, 41, 7: 1265-80.

Eraut, M. (2000) 'Non-formal learning, implicit learning and tacit knowledge in professional work' in Coffield, F. (ed.) The Necessity of Informal Learning, Bristol: The Policy Press.

Field, J. and Spence, L. (2000) 'Informal learning and social capital' in Coffield, F. (ed.) The Necessity of Informal Learning, Bristol: The Policy Press.

Forsyth, A. and Furlong, A. (2003) 'Access to Higher Education and Disadvantaged Young People', British Educational Research Journal, 29, 2: 205-225.

Garner, S. (2011) 'White working-class neighbourhoods: Common themes and policy suggestions', [Online]. Available at: http://www.jrf.org.uk/publications/white-working-class-neighbourhoods (accessed: 14 May 2014).

Gray, D. (2014) Doing Research in the Real World, 3rd ed. London: Sage Publications.

Harrison, N., Chudry, F., Waller, R. and Hatt, S. (2015) 'Towards a typology of debt attitudes among contemporary young UK under-graduates'. Journal of Further and Higher Education, 39, 1: 85-107.

Haggart, J. (2000) Learning Legacies: A Guide to Family Learning, Leicester: NIACE.

Higher Education Funding Council for England (2013) 'Trends in young participation in higher education' [Online]. Available at: www.hefce.ac.uk/media/hefce/content/pubs/2013/201328/HEFCE_2013_2 8.pdf (accessed: 20 October 2016). 
Higher Education Funding Council for England (2016) 'Our role' [Online]. Available at: http://www.hefce.ac.uk/about/role/ (accessed: 20 October 2016).

Hutchings, M. and Archer, A. (2001) 'Higher than Einstein': constructions of going to university among working-class non participants', Research Papers in Education, 16, 1: 69-91.

Ingram, N. (2009) 'Working-class boys, educational success and the misrecognition of working-class culture', British Journal of Sociology of Education, 30, 4: 421-434.

Jones, S. (2016) 'Expressions of student debt aversion and tolerance among academically able young people in low-participation English schools', British Educational Research Journal, 42, 2: 277-293.

Melcalf, H. (1993) Non-traditional Students' Experience of Higher Education: A Review of Literature, London: Committee of Vice Chancellors and Principals (CVCP).

Mills, S. and Kraftl, P. (2014) Informal Education, Childhood and Youth: Geographies, Histories, Practices, Basingstoke: Palgrave MacMillan.

Mills, S. and Kraftl, P. (2014) 'Introduction: Geographies, Histories, Practices of Informal Education' in Mills, S. and Kraftl, P. (eds) Informal Education, Childhood and Youth: Geographies, Histories, Practices, Basingstoke: Palgrave MacMillan.

Ofsted (2010) Barnsley College, [Online]. Available at: http://www.ofsted.gov.uk/inspection-reports/find-inspectionreport/provider/ELS/130524 (accessed: 16 May 2014).

Ofsted (2014) Barnsley Academy [Online]. Available at: http://www.ofsted.gov.uk/inspection-reports/find-inspectionreport/provider/ELS/131749 (accessed: 14 May 2014).

Ofsted (2016) What we do [Online]. Available at: https://www.gov.uk/government/organisations/ofsted (accessed: 20 October 2016).

One Barnsley (2008) Barnsley's Local Area Agreement [Online]. Available at: http://www.vabarnsley.org.uk/pdf/onebarnsley/barnsleylaa08.pdf (accessed 16 November 2017).

Patterson, O. (2010) 'The mechanisms of cultural reproduction: explaining the puzzle of persistence' in Hall, J., Grindstaff, L., and Lo, M. (eds) Handbook of Cultural Sociology, London: RoutledgeFalmer.

Reay, D. (2001) 'Finding or losing yourself?: working class relationships to education', Journal of Education Policy, 16, 4: 333-346.

Swidler, A. (1986) 'Culture in Action: Symbols and Strategies' American Sociological Review, 51, 2: 273-286.

Townsend, P. (1993) The International Analysis of Poverty, London: Pearson Education.

Universities United Kingdom (2015) 'Patterns and trends in UK Higher Education 2015' [Online]. Available at 
http://www.universitiesuk.ac.uk/policy-and-

analysis/reports/Documents/2015/patterns-and-trends-2015.pdf (accessed: 20 October 2016).

Voigt, K. (2007) 'Individual choice and unequal participation in higher education', Theory and Research in Education, 5, 1: 87-112.

Wacquant, L. (2008) 'Pierre Bourdieu'. in Stones, R. (ed.) Key Sociological Thinkers, Basingstoke: Palgrave Macmillan.

Watts, M. (2006) 'Disproportionate Sacrifices: Ricoeur's Theories of Justice and the Widening Participation Agenda for Higher Education in the UK', Journal of Philosophy of Education, 40, 3: 301-312.

Watts, M. \& Bridges, D. (2006) 'Enhancing students' capabilities? UK higher education and the widening participation agenda' in Deneulin, S., Nebel, M., and. Sagovsky, N. (eds) Transforming Unjust Structures: The Capability Approach, Amsterdam: Springer.

Wolf, A. (2002) Does Education Matter? Myths About Education and Economic Growth, London: Penguin Books. 